OPEN ACCESS

Study of the Binder Influence on Expansion/Contraction Behavior of Silicon Alloy Negative Electrodes for Lithium-Ion Batteries

To cite this article: Dong-Hwan Yoon et al 2020 J. Electrochem. Soc. 167160537

View the article online for updates and enhancements. 


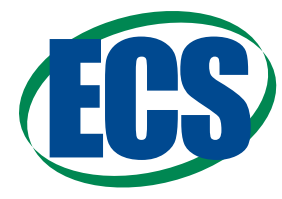

\title{
Study of the Binder Influence on Expansion/Contraction Behavior of Silicon Alloy Negative Electrodes for Lithium-Ion Batteries
}

\author{
Dong-Hwan Yoon, ${ }^{1, a, z}$ (i) Mario Marinaro, ${ }^{1}$ (i) Peter Axmann, ${ }^{1, *}$ and Margret Wohlfahrt- \\ Mehrens $^{1,2, *}$ \\ ${ }^{1}$ ZSW-Zentrum für Sonnenenergie-und Wasserstoff-Forschung Baden-Württemberg, 89081 Ulm, Germany \\ ${ }^{2}$ HIU-Helmholtz Institute Ulm, D-89081, Ulm, Germany
}

In lithium-ion batteries, Si-based materials such as silicon alloys are regarded as a promising alternative to graphite negative electrode to achieve higher energy. Unfortunately, they often suffer from a large volume change that can result in poor cycle life. We monitored the electrode expansion/contraction that occurs during lithiation/delithiation in real time by electrochemical dilatometry. Volume changes of Si alloy-based electrode with three different polymer binders have been compared. Electrode manufactured with lithiated polyacrylic acid (LiPAA) exhibited the greatest expansion but also demonstrated the highest reversibility as well as the best cycling performance. Ex situ SEM imaging along with dilatometer measurements revealed that electrode porosity after contraction (delithiation) increases compared to that after precedent expansion (lithiation), which can buffer volume expansion at the subsequent cycle. Proof-of-concept in situ optical microscopy (IOM) experiments were carried out with the best performing LiPAA electrode. The results demonstrated that LiPAA electrode in the IOM cell expanded much less than the same electrode in the dilatometer cell. This implies that internal pressure existing in a lithium-ion cell has a great impact on total electrode expansion.

(C) 2020 The Author(s). Published on behalf of The Electrochemical Society by IOP Publishing Limited. This is an open access article distributed under the terms of the Creative Commons Attribution 4.0 License (CC BY, http://creativecommons.org/licenses/ by/4.0/), which permits unrestricted reuse of the work in any medium, provided the original work is properly cited. [DOI: 10.1149/ 1945-7111/abcf4f]

Manuscript submitted September 2, 2020; revised manuscript received November 15, 2020. Published December 18, 2020.

Supplementary material for this article is available online

$\mathrm{Si}$ and Si-based materials have been attracted as a negative electrode for lithium-ion batteries in the last decades primarily due to both one order of magnitude larger theoretical capacity $\left(3579 \mathrm{mAh} \mathrm{g}^{-1}\right)$ compared to that of graphite $\left(372 \mathrm{mAh} \mathrm{g}^{-1}\right)$ and their natural abundance. ${ }^{1-9}$ However, considerably large volume change $(>280 \%)^{10}$ of such materials during charge/discharge and the resulting poor cyclability hinders implementation of large amounts of silicon into the negative electrode. ${ }^{11}$ An increasing number of studies has shown that understanding both volume change and the influence of external pressure in prototype cells made of the $\mathrm{Si}$ and $\mathrm{Si}$-based anodes is critical to improve cell performance. ${ }^{12-17}$ One promising approach to reduce overall volume expansion is to make an alloy of the active element (i.e. Si) with inactive elements (active/inactive alloys). ${ }^{18,19}$ Designing a $\mathrm{Si}$ alloy in a way that total expansion of the electrode is maintained to a tolerable amount (e.g. $100 \%$ ) results in an increased energy density as compared to that of pure $\mathrm{Si}$ with the same expansion by limiting capacity. ${ }^{2,18}$ This is mainly due to full utilization of its working potential. Another economically viable way to solve the issue of volume changes is to use effective polymeric binders. ${ }^{2,20-22}$ Effective binders can maintain the electrode integrity, leading to long term cyclability. Major roles of the binders are 1) to cohesively combine active (e.g. silicon) with inactive (e.g. conductive agent) materials; 2) to bind the materials to a current collector. ${ }^{20-25}$ An adhesion and cohesion strength is, therefore, one of the crucial properties of binder on the battery performance, which is closely related to its chemical nature.

The chemical nature of binders can be classified into three types of chemical bonds in terms of the strength and reversibility against external stress: 1) weak supramolecular interactions (e.g. van der Waals force); 2) strong supramolecular interactions (e.g. ion-dipole interactions and hydrogen bonding); and 3) covalent bonds. ${ }^{20}$ For example, polyvinylidene fluoride (PVdF) exhibits weak supramolecular interactions, which have the high reversibility, but also possess a weak driving force to return to the original state. Carboxymethyl

\footnotetext{
*Electrochemical Society Member.

${ }^{\text {a }}$ Present address: Umicore Korea Limited, 410, Chaam-dong, Cheonan, Republic of Korea.

${ }^{\mathrm{z}}$ E-mail: donghwan.yoon@zsw-bw.de
}

cellulose (CMC), polyacrylic acid (PAA), and polyvinyl alcohol (PVA) have strong supramolecular interactions, which are able to recover dissociated bonds more efficiently due to their reversibility and stronger bonds. In contrast to the former supramolecular interactions, covalent bonds forming a relatively stiff electrode structure can suppress the disintegration of active particles upon repeated volume change, but the too strong adhesion of the covalent bonds impinges on the reversibility, which eventually leads to electrode failure. ${ }^{20,26}$ Therefore, a proper choice of binder is strongly desirable in Si-based anodes to improve the mechanical stability of the electrodes and thereby improved cycle life.

Many efforts have been made on polymer binders combined with $\mathrm{Si}$ and Si-based systems to accommodate such a huge volume change, or at least, to delay the fast capacity fading by increasing mechanical stability of the electrode. ${ }^{22,27-29}$ However, there is little information available on detailed analysis of the expansion of the $\mathrm{Si}$ alloy electrodes with different binders. Recently, Raam et al. carried out electrode thickness measurements of Si alloy composites made from lithiated PAA (LiPAA) with varying molecular weights in a coin-type cell. ${ }^{30}$ The study showed that LiPAA binder with a molecular weight of $250,000 \mathrm{~g} \mathrm{~mol}^{-1}$ at concentration of $8 \mathrm{wt} . \%$ exhibited the best cycling performance though the irreversible volume expansion of the electrode was about $40 \%$ after one complete cycle. It is, however, an ex situ approach where evolution of volume changes of the electrode cannot be detected. Electrochemical dilatometry (ECD) has been regarded as method of choice to investigate Si-based anodes for the past decade. ${ }^{22,31,32}$ This is because vertical displacement of an electrode of interest is monitored in real-time with a high precision. ${ }^{25,33}$

In this study, the influence of binder type on volume change of the silicon alloy electrodes during lithiation and delithiation was systematically investigated. Since the covalent bonding between binder and silicon particle is not desirable due to the poor reversibility, two binders, LiPAA and PVA, that form the strong supramolecular interactions are selected and compared with the traditional binder PVdF. The dilatometric responses on the Si alloy electrodes with three binders (LiPAA, PVdF, and PVA) upon lithiation/delithiation were primarily monitored by electrochemical dilatometry and analyzed in detail. To support the results obtained from the dilatometry, ex situ cross-sectional SEM was used and the 
micrographs were analyzed by an image processing software, Avizo $^{\text {TM }}$. Furthermore, a proof-of-concept in situ optical microscopy was introduced to directly visualize volume change of the electrodes upon lithiation.

\section{Experimental}

Electrode preparation.-Si alloy was obtained from $3 \mathrm{M}$ company (L-20772 CV7), and used as received. Three types of electrodes were fabricated by mixing $\mathrm{Si}$ alloy and binder in a weight ratio of 91 to 9 as described in Ref. 19. The binders used in this study were lithium substituted polyacrylic acid (LiPAA), polyvinylidene fluoride (PVdF), and polyvinyl alcohol (PVA). 10 wt.\% LiPAA solution was prepared as follows: $35 \mathrm{wt} \%$ aqueous solution of polyacrylic acid (PAA, MW $=250 \mathrm{~K}$, Aldrich) was neutralized to $\mathrm{pH}=7$ by lithium hydroxide and then diluted to obtain the resulting binder solution. 5 wt.\% PVdF solution was obtained by dissolving PVdF (P5130, Solvay Solexis) in N-methyl-pyrrolidone (anhydrous, Sigma-Aldrich) by means of magnetically stirring overnight. PVA (MW $=130 \mathrm{~K}$, Sigma-Aldrich) was vigorously stirred for $1 \mathrm{~h}$ with a magnetic stirrer in deionized water by using water bath $\left(85^{\circ} \mathrm{C}\right)$ to obtain an uniform binder solution with a concentration of $6.5 \mathrm{wt} . \%$. Fritsch Pulverisette 7 planetary mill was used to mix the active material and corresponding binder. The materials were placed in $45 \mathrm{ml}$ zirconium oxide vessel with four zirconium oxide beads and mixed at $160 \mathrm{rpm}$ for $60 \mathrm{~min}$. In the case of slurry with PVA binder the slurry was mixed for $4 \mathrm{~h}$ due to formation of agglomerates. The slurries were then spread by the "doctor blade" technique on a copper foil (35 $\mu$ m-thick) supported on an automatic coater (Erichsen, Germany). The film was dried in air for at least $2 \mathrm{~h}$ and then cut into various sizes $(8 \mathrm{~mm}$ in diameter for dilatometry and $16 \mathrm{~mm}$ in diameter for in situ optical microscopy) round electrodes before being further dried in a vacuum glass oven (Büchi, Switzerland) overnight. The final loading of the three electrodes is $3.7 \pm 0.2 \mathrm{mAh} \mathrm{cm}^{-2}$.

Electrochemical testing.-Dilatation of the electrodes with different binders was monitored using an electrochemical dilatometer (ECD-1 cell, EL-CELL GmbH). The design of the ECD-1 cell was reported elsewhere. ${ }^{33}$ In the cell core, a stiff glass frit is used as separator and placed in a fixed position to measure solely the height change of the working electrode by a high-resolution displacement transducer. A dried electrode with $8 \mathrm{~mm}$ in diameter was used as working electrode and lithium metal was used as counter and reference electrodes. If not stated otherwise, the electrolyte used in this study was $1 \mathrm{M} \mathrm{LiPF}_{6}$ in EC:EMC:FEC (27:63:10, w/w). The dilatometer cells were assembled in an argonfilled glovebox $\left(<0.1 \mathrm{ppm}\right.$ both $\mathrm{O}_{2}$ and $\mathrm{H}_{2} \mathrm{O}$, MBraun). The electrochemical measurements were performed in a climate chamber (Binder $\mathrm{GmbH}$ ) where temperature inside was maintained at $25^{\circ} \mathrm{C}$. Electrochemical cycling was carried out at laboratory battery testing unit VersaSTAT 3 F (Princeton Applied Research). Constant current lithiation (to $0.005 \mathrm{~V}$ ) and delithiation (to $0.9 \mathrm{~V}$ ) with a defined $\mathrm{C}$-rate (based on a reversible capacity of $1110 \mathrm{mAh} \mathrm{g}^{-1}$ ) was applied to investigate the height changes depending on different binders. For cross-sectioning, a broad-beam Ar ion milling device (Hitachi IM4000Plus) was used. Scanning electron microscopy (SEM) imaging was performed, using a LEO $1530 \mathrm{~V}$ (Carl ZeissNTS $\mathrm{GmbH}$ ) microscope. For a visualization of the volume changes of the electrodes, in situ optical microscopy measurements were conducted on a digital optical microscope (M8, PreciPoint, Germany) equipped with a 40x objective lens (Olympus UIS2). An optical cell was designed with a two-electrode set-up as same as the conventional coin cell-type and a cross section of the cell components (i.g. anode, cathode, and separator) with windows was manufactured in order to allow observation of anode expansion. Si alloy electrodes with three different binders act as an anode, while $\mathrm{LiNi}_{0.5} \mathrm{Mn}_{0.3} \mathrm{Co}_{0.2} \mathrm{O}_{2}$ (denoted "NMC" hereafter, Umicore, Belgium) cathodes serve as a cathode $\left(3.5 \mathrm{mAh} \mathrm{cm}^{-2}\right)$. The detailed coating procedures of NMC cathode were reported elsewhere. ${ }^{34}$ Celgard $^{\circledR}$ 2325 was used as a separator. The cells were cycled at $\mathrm{C} / 20$ with an upper voltage cutoff of $4.2 \mathrm{~V}$ using a potentiostat/galvanostat (Vertex.One, IVIUM, Netherlands).

Porosity determination.-Porosities were determined for the pristine, the fully lithiated, and the fully delithiated LiPAAcontaining electrodes, using the cross-sectioning device, SEM, and an image processing software, Avizo ${ }^{\mathrm{TM}}$. Once the electrodes were either lithiated or delithiated in the dilatometer, the dilatometer cell was disassembled and the electrodes were carefully washed with dimethyl carbonate (DMC) in an Ar-filled glove box. The washed electrodes were then dried under vacuum before being milled by $\mathrm{Ar}$ ion beam to obtain a cross-section. In the case of the lithiated electrode, a specially designed transfer chamber was used for crosssectioning and SEM investigations. The key for accurate digital porosity analysis is to generate a threshold image which separate the pores from the rest of the objects in the image. The secondary electrons (SE) images of all three electrodes were used to obtain representative cross-sections of the electrodes.

\section{Results and Discussion}

We studied first, by means of electrochemical dilatometer, how the type of binder affects the thickness change of the silicon alloy anode during lithiation and delithiation. In the dilatometer setup, the Si alloy anode, which acts as the working electrode, is mounted on top of a glass frit that mechanically isolates the electrode from the $\mathrm{Li}$ metal counter electrode. The real-time thickness variation (i.e. vertical expansion and contraction) is monitored through a thin metal membrane by a linear voltage displacement transducer. The measured changes of the electrode thickness are then converted to the percentage thickness change (\%) by using following equation,

$$
\Delta h(\%)=\frac{h_{f}-h_{i}}{h_{i}} \times 100
$$

where $h_{f}$ and $h_{i}$ are the final and initial thickness of the electrode.

The continuous thickness changes of the electrodes prepared with LiPAA, PVdF, and PVA binders during cycling are shown in Fig. 1. The first and second cycle capacities and thickness changes $(\%)$ of the electrodes with different binders after each half cycle are also summarized in Table I. Note that electrode thicknesses are set as zero after soaking in the electrolyte (i.e. the initial state). A common observation in Fig. 1 is that all electrodes severely expand $(>180 \%)$ upon lithiation ( $\mathrm{Li}-\mathrm{Si}$ alloying) and contract upon delithiation $(\mathrm{Li}-\mathrm{Si}$ de-alloying), although the extent and behavior of expansion/contraction differ depending upon the selected binders. ${ }^{22,23,25,35} \mathrm{We}$ note that a non-linear thickness change as function of the run time, that is proportional to capacity, is observed. This is contradictory to the expected linear behavior of $\mathrm{Li}-\mathrm{Si}$ alloying. ${ }^{18}$ Linear volume expansion of alloy anode materials as a function of lithium content has been reported by Obrovac et al., which derives from binary phase diagrams of lithium-hosting metals such as $\mathrm{Si}$ or $\mathrm{Sn}$ with lithium. ${ }^{18}$ In the case of $\mathrm{Si}$, addition of lithium at temperature near $400{ }^{\circ} \mathrm{C}$ forms a series of crystalline $\mathrm{Si}-\mathrm{Li}$ phases, whereas lithiation of silicon at near or room temperature did not show those phases. Instead, silicon becomes amorphous upon lithiation ${ }^{36}$ and a metastable $\mathrm{Li}_{15} \mathrm{Si}_{4}$ phase might be obtained at the end of lithiation. ${ }^{10}$ Nevertheless, room temperature lithiation of silicon is expected to follow the linear expansion. ${ }^{22}$ Therefore, the observed nonlinearity seems to reflect an effect of binder at the electrode level.

Electrodes made with LiPAA do not swell significantly for the first $2 \mathrm{~h}$. Both PVdF- and PVA-based electrodes also show a slow and small thickness increase up to $3 \mathrm{~h}$. The slow expansion can presumably be attributed to the capability of the initial electrode porosity to accommodate the volume changes. ${ }^{22,25,32}$ Afterwards, a fast and linear thickness increase $\left(1.31 \%\right.$ per $\left.\mathrm{mAh} \mathrm{g}^{-1}\right)$ is observed. Then, expansion rate decreases progressively as the first lithiation 
Table I. First and second cycle (de)lithiation capacity and thickness change of LiPAA, PVdF, PVA-based electrodes.

\begin{tabular}{|c|c|c|c|c|c|c|c|c|}
\hline \multirow[b]{2}{*}{ Binder } & \multicolumn{4}{|c|}{ 1st Cycle } & \multicolumn{4}{|c|}{ 2nd Cycle } \\
\hline & $\mathrm{Q}_{\text {lith }}\left(\mathrm{mAh} \mathrm{g}^{-1}\right)$ & $\mathrm{T}_{\text {lith }}(\%)$ & $\mathrm{Q}_{\text {delith }}$ & $\mathrm{T}_{\text {delith }}$ & $\mathrm{Q}_{\text {lith }}$ & $\mathrm{T}_{\text {lith }}$ & $Q_{\text {delith }}$ & $\mathrm{T}_{\text {delith }}$ \\
\hline LiPAA & 1136 & 490 & 837 & 94 & 902 & 441 & 810 & 97 \\
\hline $\mathrm{PVdF}$ & 1193 & 230 & 526 & 70 & 465 & 153 & 119 & 117 \\
\hline PVA & 827 & 169 & 419 & 57 & 220 & 93 & 150 & 60 \\
\hline
\end{tabular}

reaches the end criteria $\left(\mathrm{E}_{\text {Cutoff }}=0.005 \mathrm{~V}\right)$, resulting in $490 \%$ swelling at full lithiation, which is in line with, at least in terms of the extent, some of the previous measurements carried out by dilatometer in literature. Yu et al. reported $450 \%$ expansion at the end of lithiation (3400 $\mathrm{mAh} \mathrm{g}^{-1}$ ) when CMC and micro-size silicon $(5 \mu \mathrm{m})$ were used in a weight ratio of $20: 60$ with $20 \mathrm{wt} . \%$ conductive carbon. ${ }^{22}$ In their publication, approximately $300 \%$ expansion during the last stage of lithiation was attributed to "the breakdown of the binder and cracking of the particles." Tranchot et al. showed $350 \%-500 \%$ expansion for the first two cycles when 8 wt.\% CMC and $80 \mathrm{wt} . \%$ silicon with $85 \mathrm{~nm}$ particles were used. ${ }^{32}$ The rupture of the cohesive $\mathrm{Si}-\mathrm{CMC}$ bond was pointed out for the reason of such an expansion. In the present study, however, the fact that the large electrode expansion is detrimental, and possibly due to either the breakdown of the binder or the rupture of the Si-binder bonds, could not be fully confirmed because the most expanded LiPAA electrodes showed the lowest capacity fading as well as the highest reversibility. An early study shows that PAA contains high concentration of carboxylic groups, which form strong hydrogen bonds with $\mathrm{OH}$ groups on the $\mathrm{Si}^{21}$ Moreover, LiPAA mainly forms ionically conductive COOLi groups, which might build a stable SEI and exhibit ion-dipole interaction. These are presumably responsible for the reversibility of LiPAA electrodes.

Interestingly, an abrupt contraction of the electrode starts at $\sim 20.8 \mathrm{~h}$ during the first delithiation that is followed by a dramatically slow decrease in thickness. Although the phenomena observed here are not yet clearly understood, the similar abrupt contraction has been reported. ${ }^{23,32}$ Tranchot et al. attributed such a thickness decrease to electrode decohesion resulting from the rupture of the Si-binder bonds during lithiation-induced volume expansion. The acoustic emission (AE) activity that is originated from cracking of the active material, SEI formation, and gas evolution was also observed intensively at the beginning of delithiation of the silicon electrode. ${ }^{32}$

At the end of the first cycle, the amount of remaining expansion (i.e. irreversible volume change, Virr) of the LiPAA electrode is $94 \%$, exhibiting the highest reversibility ( $81 \%$ of total expansion is recovered) among the three electrodes tested here (also see Table I). This result indicates that the best cycling performance is achieved using LiPAA. The first cycle coulombic efficiency (CE) is $73.7 \%$, lower than the result obtained from electrodes with same composition evaluated in a coin cell-type geometry. ${ }^{37}$ This is most likely due to lower pressure applied in the ECD-1 cell that is originated from the intrinsic concept of measuring the out-of-plane volume change by a displacement sensor without applying excessive pressure, ${ }^{33,38}$ which cannot sufficiently prevent particle movements and coating detachment during a course of expansion and contraction. In fact, Berckmans et al. demonstrated that applying external pressure on $\mathrm{Si}$ alloy-containing cells is beneficial in terms of capacity and ohmic resistance during discharge. ${ }^{14}$

When the second lithiation starts, the expansion behavior of the LiPAA electrode is altered. A slow and continuous volume expansion occurs for $\sim 8 \mathrm{~h}\left(440 \mathrm{mAh} \mathrm{g}^{-1}\right)$ followed by a steep increase in thickness up to $441 \%$ at the end of lithiation. During the second delithiation, contraction behavior is comparable to that of the first delithiation. The irreversible expansion after the second cycle (97\%) is only increased by $3 \%$ with respect to the first cycle, indicative of a reversible volume change of the LiPAA containing electrode. The $\mathrm{CE}$ for the second cycle is also increased to $89.8 \%$, indicating that the electrode is better passivated (after SEI formation).
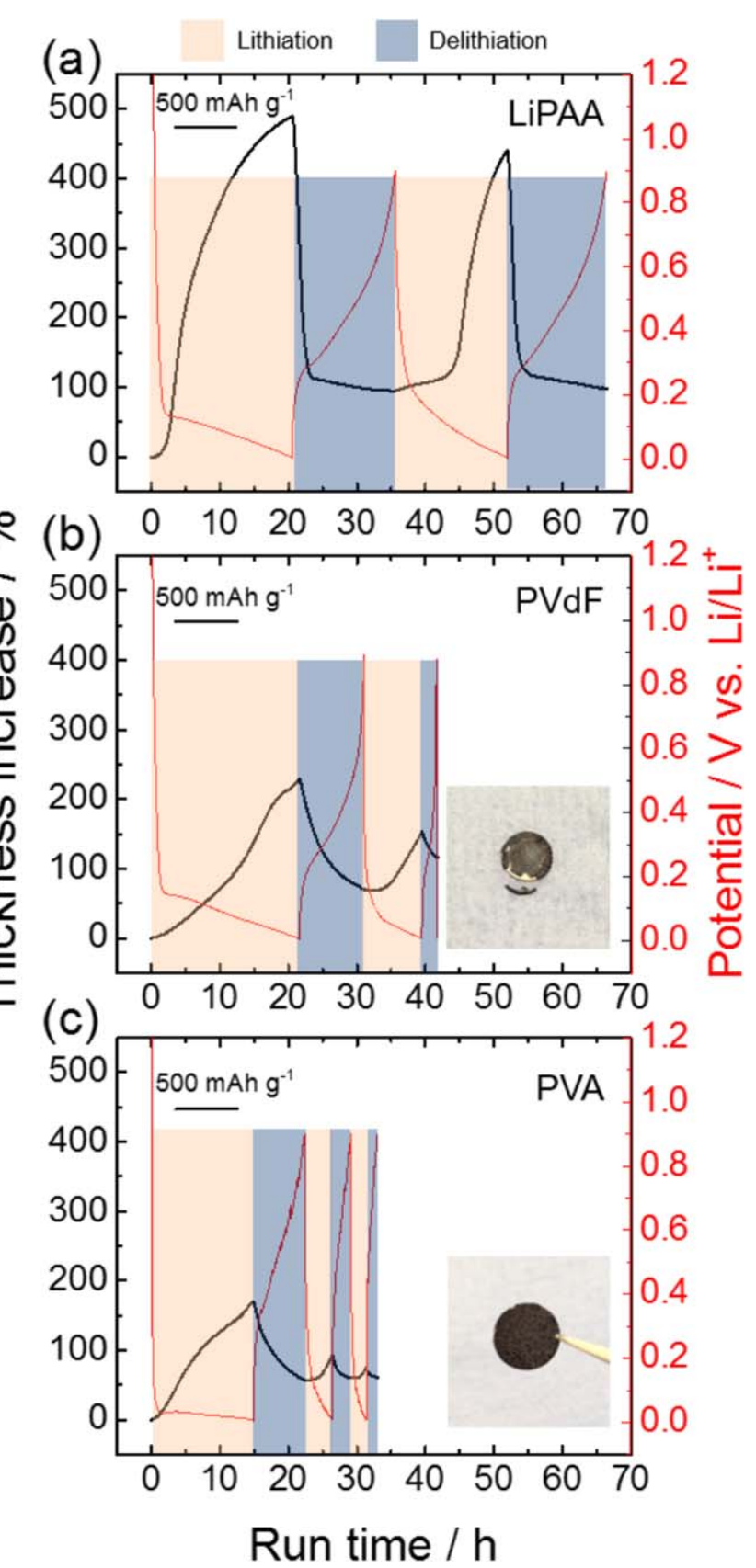

Figure 1. Thickness change of silicon alloy anodes with (a) LiPAA, with (b) PVdF, and with (c) PVA during galvanostatic cycling (C/20 as being $55 \mathrm{~mA} \mathrm{~g}^{-1}$ alloy). Black lines show evolution of the electrode thickness, whereas red thin lines depict potential of the anodes vs $\mathrm{Li}^{\prime} / \mathrm{Li}^{+}$. The legend in each figure corresponds to a capacity of $500 \mathrm{mAh} \mathrm{g}^{-1}$.

The expansion/contraction behavior of PVdF-based electrode is different from the one with LiPAA. (Fig. 1b). First, the expansion of the electrode only reaches to $230 \%$ at full lithiation with a 
comparable capacity of $1193 \mathrm{mAh} \mathrm{g}^{-1}$ that is approximately half the expansion of LiPAA electrode. However, the PVdF electrode shows poor capacity retention. Indeed, nearly no capacity was obtained during the third cycle. Second, the expansion rate continuously increases during lithiation and the last ramp-up in thickness starting at $\sim 16 \mathrm{~h}$ is presumably due to the binder breakdown, which can accelerate both cohesion (particle-to-particle) and adhesion (particleto-current collector) failure modes (see Fig. 1b inset). After the ramp-up, the slope of thickness increase is levelled at $20 \mathrm{~h}$ and then the increases again until the end of the lithiation. A repeated measurement of the PVdF electrode (not shown here) even exhibits a slight decrease in thickness (i.e. contraction) followed by the thickness increase again during the first lithiation. The similar features were reported when silicon was prepared with neutralized CMC (see Fig. 5c in Ref. 19). They attributed the observation to the collapse of the electrode structure originated from its poor cohesive nature. As seen in the picture of the electrode taken after three cycles, the PVdF electrode was cracked and delaminated from the current collector. Although used binders are different in this comparison, it is reasonable to conclude that the binder which possesses a poor cohesive property can lead to cracks, delamination, and collapse of its structure, which even results in a decrease in thickness while being lithiated. All those effects translate into a reduced delithiation capacity (526 $\left.\mathrm{mAh} \mathrm{g}^{-1}\right)$, low coloumbic efficiency (44.1\%) and high irreversible expansion after the first cycle. Indeed, only $70 \%$ of the total expansion is recovered during delithiation. After the second cycle, the PVdF-containing electrode contracts only $36 \%$ (from $153 \%$ to $117 \%$ ), since most of the active particles are likely electrically disconnected at this stage. Irreversible volume expansion after the second delithiation is further increased to $117 \%$ (c.f. $70 \%$ after the 1 st delithiation).

Figure 1c shows the expansion/contraction behavior of PVAbased electrode. The expansion of the PVA electrodes behaves differently from that of the PVdF electrodes, whereas it shows a similar trend as that of the LiPAA electrodes. After a slow increase for the first $1.3 \mathrm{~h}$ due to the buffering property of the initial pores, as shown on the other electrodes, the expansion rate for the next $5 \mathrm{~h}$ is higher $\left(0.291 \%\right.$ per $\left.\mathrm{mAh} \mathrm{g}^{-1}\right)$ than the region between 3 and $12 \mathrm{~h}$ in PVdF-based electrode $\left(0.161 \%\right.$ per $\left.\mathrm{mAh} \mathrm{g}^{-1}\right)$. Possible explanation is that rather strong hydrogen bonding (i.e. strong supramolecular interaction) between binder and active material allows less particle rearrangement compared to the electrode made from PVdF. While $\mathrm{PVdF}$ is more flexible due to the weak van der Waals interaction with the silicon alloy, PVA interacts rather strongly with the active material. ${ }^{20}$ This will be further discussed with a model below. At the end of lithiation, the expansion rate for the electrode made from PVA becomes lower similarly to as the LiPAA electrode. It is hypothesized that each particle expands from its original location and might leave pore spaces, which can then accommodate the expansion by filling the voids. The expansion due to the first lithiation is $169 \%$, which is the lowest among the three electrodes tested, partially due to the less capacity achieved $\left(827 \mathrm{mAh} \mathrm{g}^{-1}\right)$. Comparing the potential profiles, $\mathrm{Li}-\mathrm{Si}$ alloying reaction in electrodes made from LiPAA and PVdF occurs at approximately $0.14 \mathrm{~V}$ vs $\mathrm{Li} / \mathrm{Li}^{+}$, whereas the reaction in PVA electrode takes place at $0.03-0.04 \mathrm{~V}$, thus possibly indicating high electrode resistance and slower kinetics. Since the lithiation was carried out under constant current scheme without a constant voltage scheme and the overpotential of PVA electrode was apparently larger, the capacity gained for the first lithiation of PVA electrode is lower than the previous two electrodes. When the constant current-constant voltage (CCCV) lithiation was carried out in a coin cell, a comparable lithiation $\left(1137 \mathrm{mAh} \mathrm{g}^{-1}\right)$ and delithiation capacity $\left(870 \mathrm{mAh} \mathrm{g}{ }^{-1}\right)$ to LiPAA electrode were obtained (see Fig. S1 available online at stacks.iop.org/JES/167/160537/mmedia in supplementary information). In addition, the PVA electrodes shrink back to $60 \%$ after the second cycle, which is almost the original state at the beginning of the second lithiation (57\%) although delithiation capacity was only obtained $150 \mathrm{mAh} \mathrm{g}^{-1}$.

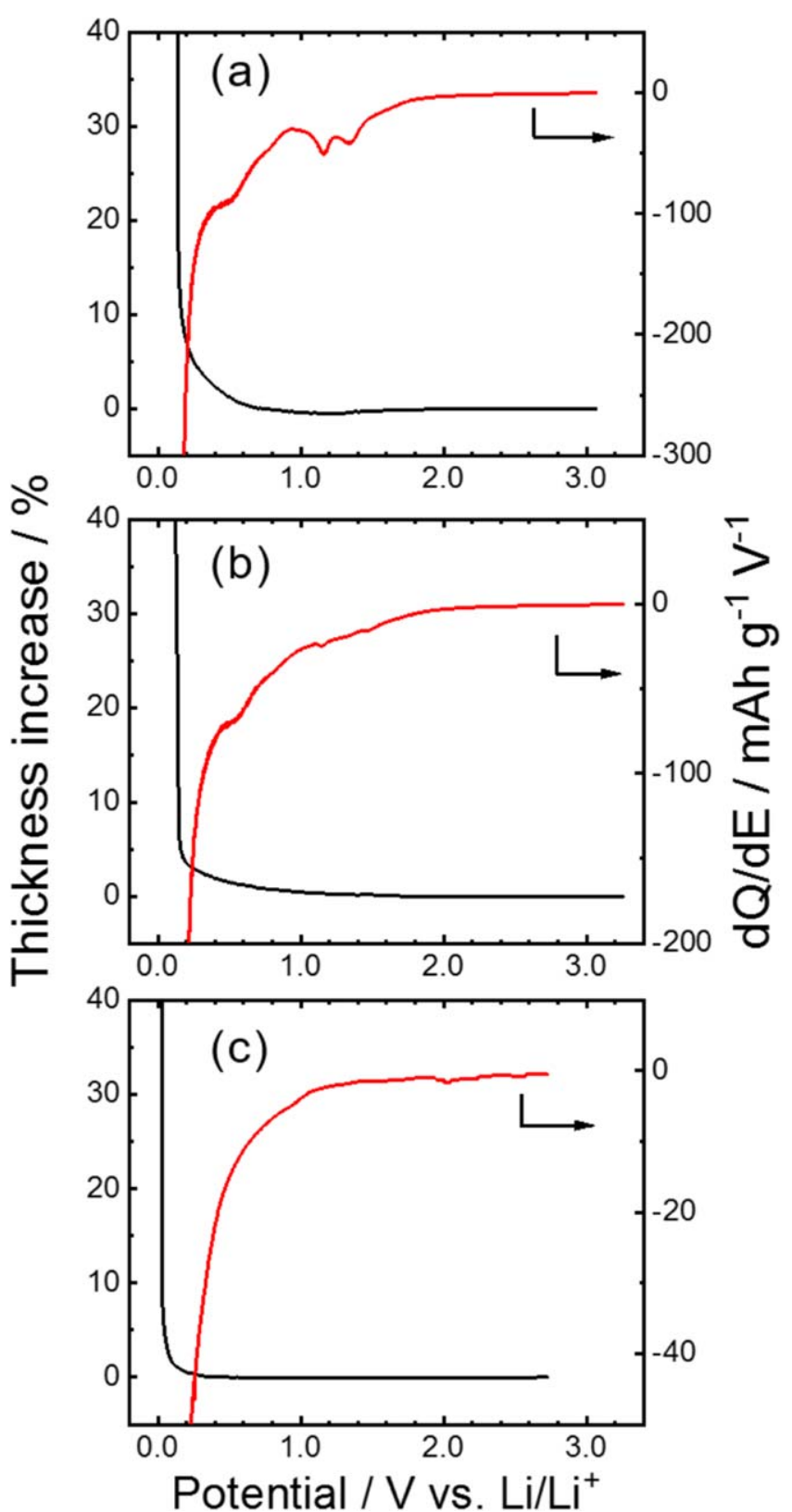

Figure 2. Evolution of thickness change and differential capacity $(\mathrm{dQ} / \mathrm{dE})$ for the early stage of first lithiation in the potential window from open circuit voltage ( $\sim 3 \mathrm{~V})$ to $0 \mathrm{~V}$ for (a) LiPAA, (b) PVdF, and (c) PVA electrode.

Height changes of the electrodes and differential capacity $(\mathrm{dQ} / \mathrm{dE})$ during the first and second cycles are depicted in Figs. 2 and 3. In the vicinities of the SEI formation potential, as shown in Fig. 2, the reductive decomposition of the electrolyte components is denoted by two pronounced peaks, in accordance with previous studies ${ }^{39-41}$ However, the peaks in LiPAA-containing electrode are more pronounced than the ones with PVdF (Figs. 2a and 2b). As reported in literature, ${ }^{8,37,42-44}$ FEC plays a key role as a film forming agent on silicon- and silicon alloy-based electrodes and decomposes to form a SEI earlier than other components of the main electrolyte. When the SEI is formed on the surface of silicon alloy particles, there is no clear indication of volume expansion at these potentials at the electrode level. Traditional SEI on lithium metal is a nanometerscale film with $25-100 \AA,^{45,46}$ having properties of electronic insulator and ionic conductor, while the total thickness of SEI on silicon nanowires was reported $22 \mathrm{~nm}$ after the first cycle, ${ }^{47}$ which is significantly thicker, but still in nanometer-scale. Therefore, the 
(a)
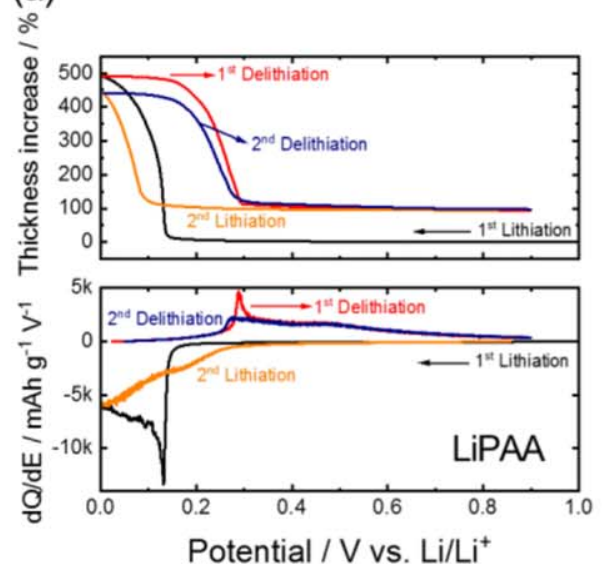

(b)
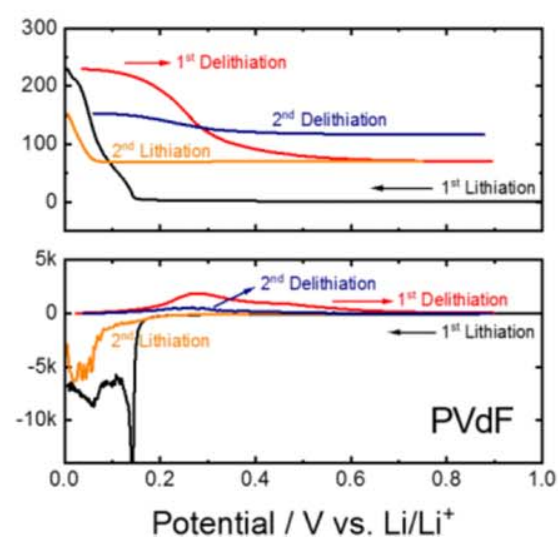

(c)

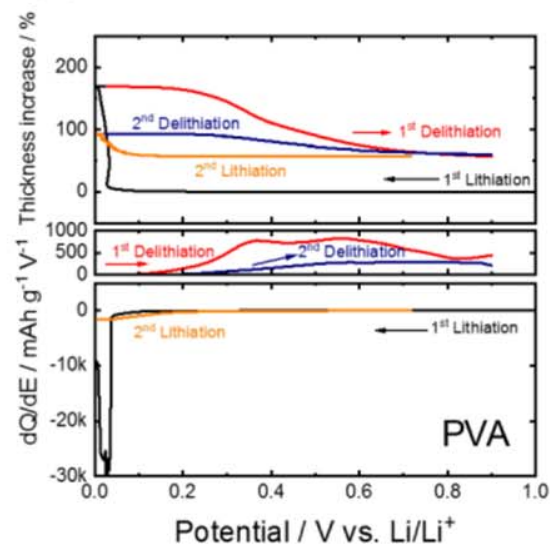

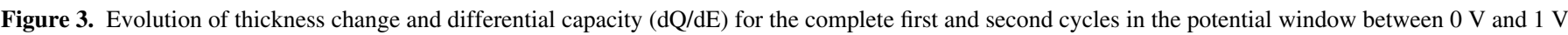
for (a) LiPAA, (b) PVdF, and (c) PVA electrode.

early stage of the SEI film formation in the Si-alloy anodes is unlikely to contribute out-of-plane expansion at the electrode level as evidenced in Fig. 2. Another explanation would be that SEI layers formed on the surface of particles might also be accommodated by the pores present inside the electrodes.

Contrary to the previous two electrodes, the peak associated to the reduction of the electrolyte is barely noticeable when PVA was used (Fig. 2c), and found at ca. 1.3 V. When the PVA electrode was cycled in a coin cell, the reduction peak was more discernible at 1.24 V (see Fig. S1). This suggests that PVA may form an insulating film on the active materials, leading to a large overpotential as evident in the voltage profile (Fig. 1c) and/or SEI formation on the PVA electrodes is sluggish. ${ }^{5}$ Again, there is no clear indication of vertical expansion on PVA-based electrodes during SEI formation as observed on LiPAA- and PVdF-based electrodes.

When the 1 st $\mathrm{Li}-\mathrm{Si}$ alloying reaction occurs at $0.15 \mathrm{~V}$ vs $\mathrm{Li} / \mathrm{Li}^{+}$ for the LiPAA-containing electrodes (Fig. 3a) and $0.16 \mathrm{~V}$ for PVdFcontaining electrode (Fig. 3b), the volume expansion for both cases is delayed to occur at $0.14 \mathrm{~V}$. For both electrode types, the initial electrode porosity seems to offer free space for particles to expand, and thereby the early stage expansion of the electrode is buffered by filling the voids inside the electrode. Lithiation for PVA-containing electrode begins at much lower potential $\left(\sim 0.04 \mathrm{~V}\right.$ vs $\left.\mathrm{Li}^{\prime} \mathrm{Li}^{+}\right)$ compared to the former two presumably due to the considerably slower electrode kinetics. As similar as before, the vertical expansion of PVA electrode starts at even lower potential (Fig. 3c). Overall, the expansion onsets for the first lithiation are slightly shifted to lower potentials owing to pores present in the pristine electrodes.

One noticeable feature on the $\mathrm{dQ} / \mathrm{dE}$ profiles during delithiation is two smooth humps centered at $0.29 \mathrm{~V}$ and at $0.46 \mathrm{~V}$, as shown in Fig. 3. As reported about this type material in literature, ${ }^{19}$ the two humps indicate silicon in the alloy is being cycled in a single phase. The metastable final phase, $\mathrm{Li}_{15} \mathrm{Si}_{4}$, is avoided to form at the end of lithiation presumably due to stress induced from the presence of the inactive phase in this silicon alloy. ${ }^{48}$

Upon the second lithiation, onset of the expansion is further delayed in all three electrodes as the electrodes shrink during delithiation and probably leave pores, which then provides a space for accommodating the subsequent volume expansion. Cross section micrographs by SEM support this hypothesis that porosity of the electrodes increases after delithiation compared to that of the lithiated electrodes, which will be discussed below. Due to the sloping potential coming from single phase Li-Si alloying reaction, it is not trivial to define the onset potential of lithiation. For example, the 2nd lithiation occurs at approximately $0.38 \mathrm{~V}$ for the LiPAA electrode, whereas the volume expansion begins at $0.11 \mathrm{~V} \mathrm{vs} \mathrm{Li} / \mathrm{Li}^{+}$, which is much delayed when compared to the same feature in the $1 \mathrm{st}$ lithiation.

To better understand how the porosity changes before and after lithiation/delithiation three LiPAA-containing electrodes were prepared: the pristine, the fully lithiated, and the fully delithiated, and the cross-sections of the electrodes are shown in Fig. 4. Three representative SEM images were chosen for each electrode, as one of each case are shown in Figs. $4 \mathrm{a}-4 \mathrm{c}$. Note that the electrodes here were electrochemically lithiated/delithiated in the same dilatometer apparatus as described in Experimental section in order to achieve a fair comparison with the results of the previous section. It should be noted that digital porosity analysis by $2 \mathrm{D}$ cross-sectional SEM is semi quantitative approach. In other words, a trend in porosity changes before and after (de)lithiation is more meaningful than its absolute values. It is assumed that calculated porosity from $2 \mathrm{D}$ images (i.e. the proportion of a pore area to an entire sample area) can also be expanded pore volume in 3D structure. It is also assumed that coating is homogeneous. Therefore, the porosity from $2 \mathrm{D}$ image analysis can presumably project as similar as that from 3D structure analyzed by micro X-ray computed tomography or focused-ion beam SEM. Porosity of each entire image was calculated by Avizo $^{\mathrm{TM}}$ and average values for each electrode are displayed in Fig. 4d. Si alloy particles and pores, as well as the $\mathrm{Cu}$ current collector are clearly identified in the pristine electrode. When the electrode is lithiated (i.e. expansion), pores are reduced and most space between particles is covered by a dark contrasted layer comprising light elements such as $\mathrm{O}$, and $\mathrm{F}$ (see Fig. S2).

As mentioned earlier, particle expansion by $\mathrm{Li}-\mathrm{Si}$ alloying process during lithiation is buffered by filling pore volume at the early stage. Once initial pores are filled by expanded particles, further alloying reaction leads to a vertical electrode expansion by pushing neighboring particles as measured by dilatometer. Therefore, the porosity after lithiation is, in general, expected to decrease as compared to that of the pristine electrode. During delithiation, Si alloy particles shrink and may leave empty space, leading to an increase in porosity (Fig. 4d). The calculated porosities from image analysis for the pristine, lithiated, and delithiated electrodes are in accordance with the above-mentioned interpretation as presented in Fig. $4 \mathrm{~d}$.

To better understand why the quick contraction occurs at the beginning of each delithiation for the most reversible electrode, i.e. LiPAA electrode, a series of OCV periods have been imposed after a certain lithiation degree of the electrode, as shown in Fig. 5. This may give a clue whether a current-free relaxation during OCV is associated with the behavior of electrode contraction. After the first full lithiation, $3 \mathrm{~h}$ of $\mathrm{OCV}$ was imposed before the first full delithiation. During the subsequent cycle (2nd cycle), lithiation 

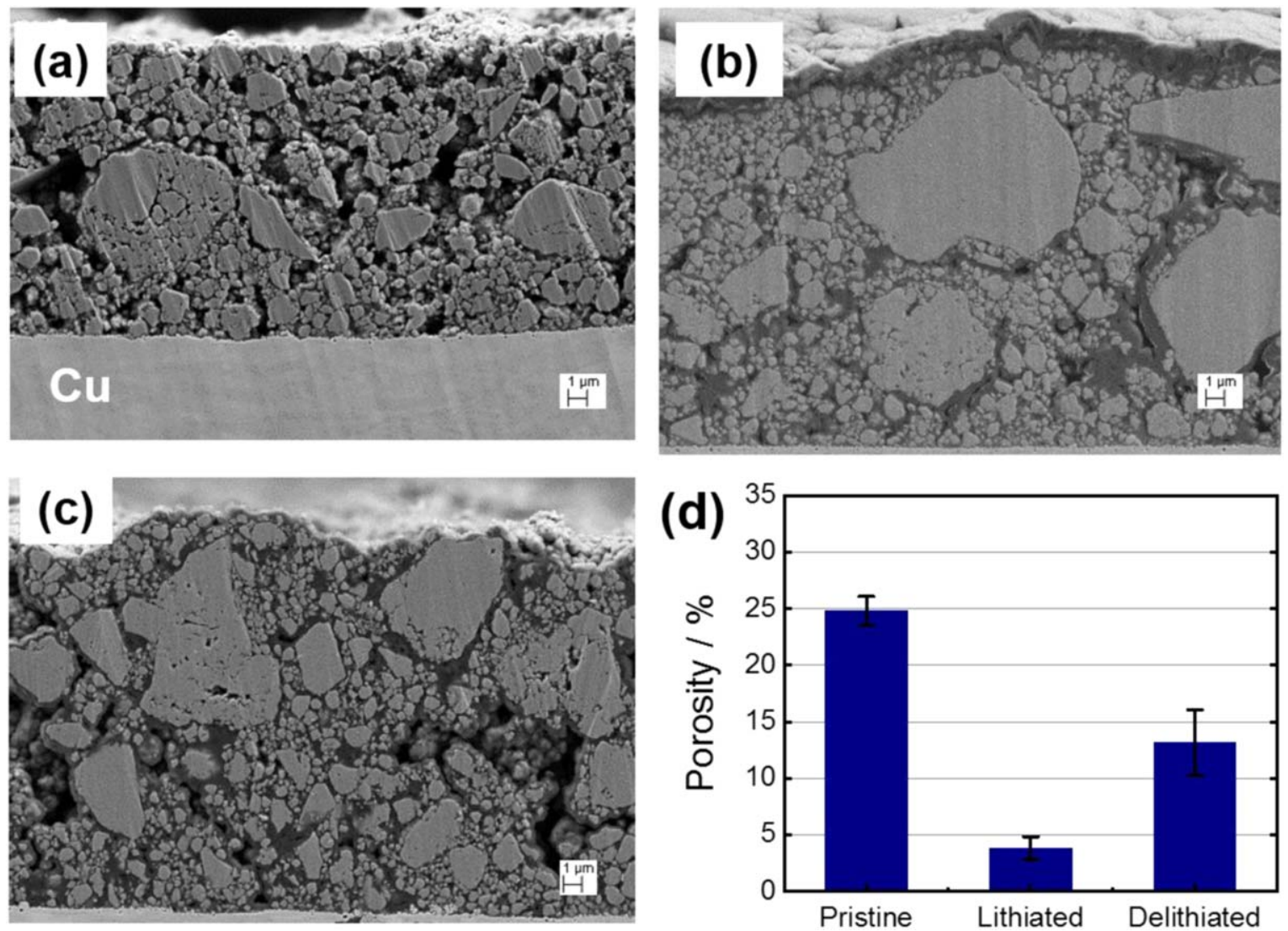

Figure 4. Secondary electron images of the cross section of (a) pristine, (b) lithiated, and (c) delithiated electrode with LiPAA binder. Porosity of each electrode is calculated via the image analysis with the aid of Avizo ${ }^{\mathrm{TM}}$. Three images (each of $2048 \times 1536$ pixels) are attained for each electrode and porosity of each image is calculated. The values in (d) are attained from an average of three images.

was limited by $8 \mathrm{~h}$ and then the second delithiation started after $3 \mathrm{~h}$ of OCV period. More lithium was inserted in the third cycle, where the lithium amount is controlled again by time $(11 \mathrm{~h})$. Then, no capacity limitation was applied in the fourth cycle (only cutoff potential limited).

When the LiPAA electrode is fully lithiated for the first time and then $3 \mathrm{~h}$ of OCV (the region labeled as "I") is imposed, the electrode contraction was observed just $22 \%$. The rate of thickness decrease is $\sim 7 \%$ per hour, which is significantly lower than the region ("II") in the subsequent 1st delithiation (127\% per hour). A reasonable interpretation on contraction/expansion behaviors of the LiPAA electrode would probably be deduced from a recent study by Kumar et al. ${ }^{23}$ Kumar and co-workers showed in-plane stress measurements and out-of-plane expansion/contraction measurements of siliconcarbon composite electrodes by using a multi-beam optical sensor technique and the dilatometry, respectively. During the first delithiation, regardless of the silicon content in the composite electrodes, a rapid decrease in compressive stress is observed at the initial stage of the delithiation. After the fast decay of the stress within short time, the rate of the stress decrease becomes significantly slower until the end of the delithiation. The stress measurements for the subsequent delithiation cycles (the 2nd and 3rd) exhibit such a clear transition, too. Dilatometry results also showed that during the early stage of the first delithiation, the electrode thickness substantially decreases, which is then followed by a slow decrease in thickness. Kumar et al. attributed these abrupt decreases in stress and in thickness at the early stage of delithiation to "elastic unloading of the binder." In other words, the binders examined (CMC and Na-alginate), which are supposedly sandwiched between the active particles, exhibit elastic recovery when a part of the load originating from silicon particle expansion is removed. Perhaps, most portion of the binders at this stage does not break down and their elastic properties are still retained. Since our dilatometry results exhibit similar trends during delithiation (the 1st, 3rd, and 4th), despite the difference of the binder used here (i.e. LiPAA), the sudden decrease in thickness can be attributed to the elastic response of the binder, which is triggered not by the current-free relaxation during $3 \mathrm{~h}$ of $\mathrm{OCV}$, but by a removal of small quantity of lithium.

Interestingly, a fast rise in thickness during lithiation processes (labeled as "III"), except that for the 1st lithiation, occurs at $\sim 420 \mathrm{mAh} \mathrm{g}^{-1}$. For example, when lithiation was carried out only for $8 \mathrm{~h}$ shown in Fig. 5b, the sudden increase in thickness was not observed. However, the fast thickness increases were observed when more lithiation was carried out as shown in Figs. 5c and 5d. Although the exact reason for this result is unclear, we believe that there might be a threshold capacity, which can cause the quick increase in electrode thickness. Furthermore, expansion/contraction behavior for the 2nd, 3rd, and 4th cycles is similar, whereas the first expansion clearly differs from the subsequent expansions. Since Si-based materials including this $\mathrm{Si}$ alloy undergo electrochemical amorphization at the first lithiation ${ }^{36}$ and then are cycled in amorphous phases, the changes in microstructure of the alloy during the 1st lithiation differs from those during the subsequent cycles. Therefore, the similarity observed might be associated with similar microstructural changes of the $\mathrm{Si}$ alloy, which occur in a single phase. The different expansion behavior between the first and the rest cycle might also be related to the structural changes.

Although in situ electrochemical dilatometry provides in depth information on the time-resolved volume changes of the electrodes, in the current dilatometer there is no stacking pressure that is present in a practical coin cell, which might cause an overestimation of the electrode thickness. ${ }^{3,12-15}$ While ex situ cross-sectional SEM approach enables a visual observation of the volume changes, it was carried out from recovered (i.e. disassembled, washed, and dried) 
(a)
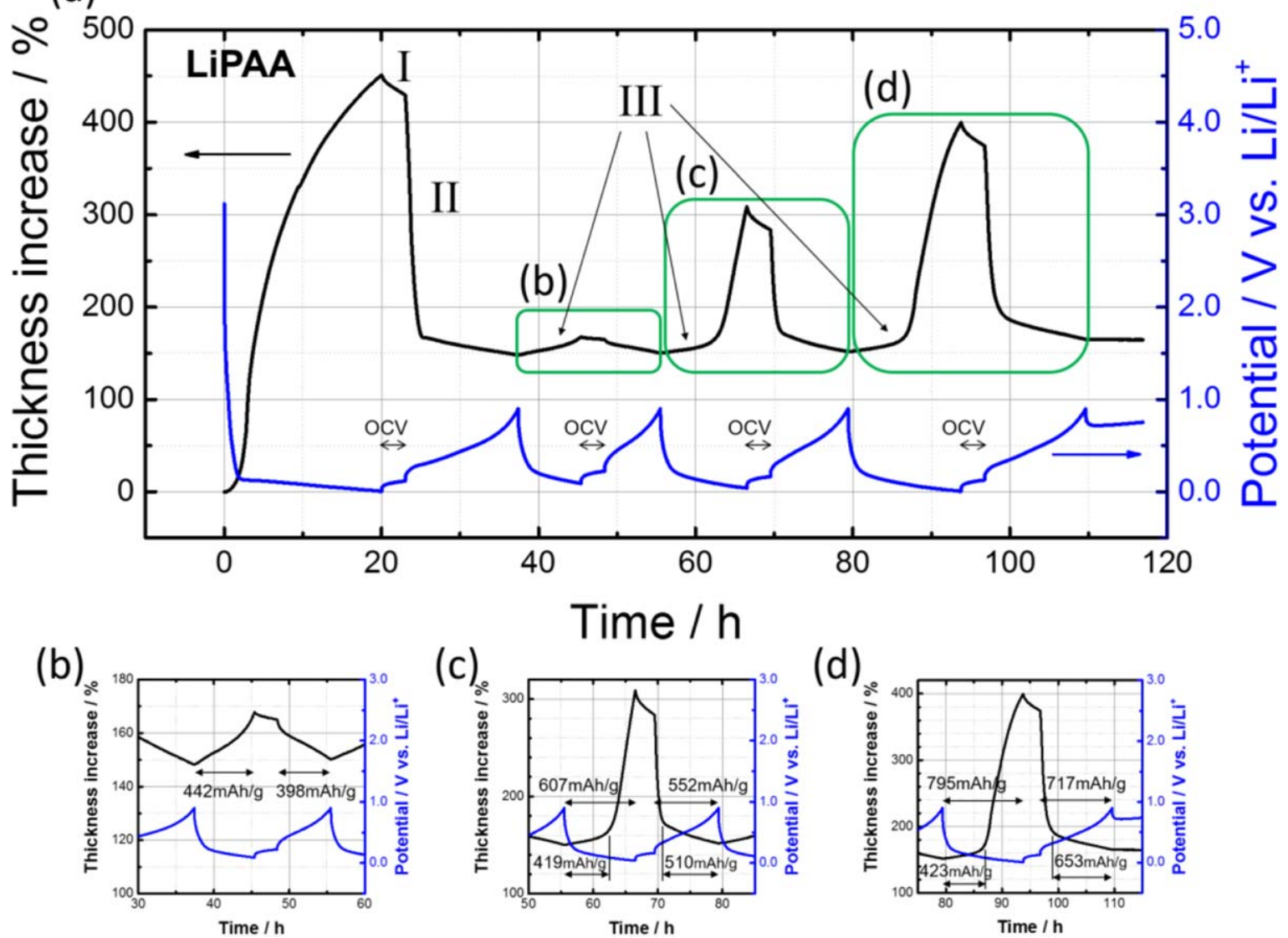

(d)

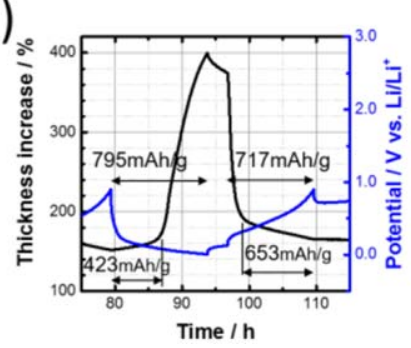

Figure 5. (a) Electrode thickness and potential response during galvanostatic cycles $(\mathrm{C} / 20)$ with open circuit interrupts for $3 \mathrm{~h}$ at full lithiation, at capacity limited lithiation $(8 \mathrm{~h})$, at $11 \mathrm{~h}$ lithiation, and at full lithiation $\left(\mathrm{E}_{\text {Cutoff }}=0.005 \mathrm{~V}\right.$ vs Li/ $/ \mathrm{Li}^{+}$) again. (b) The second, (c) third, and (d) fourth lithiation and delithiation cycles are enlarged.

and relaxed (i.e. without the stacking pressure) electrodes. The conditions with which the above mentioned two methods were carried out might not forecast correctly practical cases. Therefore, the proof-of-concept in situ optical microscopy (IOM) technique featuring the existence of the stacking pressure as well as real time visualization of volume changes is demonstrated.

Figure 6 depicts evolution of cell voltage and selected images taken during the first lithiation of the Si alloy anode with LiPAA binder against a NMC cathode in full cell. Figure 6a shows that the thickness of the silicon alloy anode gradually increases upon constant current lithiation. Note that the thickness of the silicon alloy anode was determined by measuring the total length from the $\mathrm{Cu}$ current collector to the interface between separator and NMC cathode and then subtracting a sum of the $\mathrm{Cu}$ and separator. The reason is that the interface between anode and separator becomes rougher during lithiation ${ }^{49}$ and thereby being hard to define it. It is here assumed that the thickness of Celgard ${ }^{\circledR}$ separator remains constant. As lithiation of the anode proceeds, a film-like structure is formed at the interface between the anode and separator, as shown in Fig. $6 \mathrm{~b}$ from No. 5 to 7 , which is presumably due to electrolyte decomposition products. At $470 \mathrm{mAh} \mathrm{g}^{-1}$ based on anode active material (No. 7), the thickness becomes $102 \%$, which is significantly lower than $328 \%$ at equivalent specific capacity obtained from dilatometry measurement (Fig. 1a). This clearly indicates that the stacking pressure in the cell has a great influence on electrode outof-plane expansion.

Assuming that the amount of active silicon in the alloy material is $31 \mathrm{wt} . \%$ based on the obtained alloy capacity and the theoretical Si capacity (i.e. $\left.3579 \mathrm{mAh} \mathrm{g}^{-1}\right),{ }^{10}$ the thickness increase is redrawn with respect to the silicon specific capacity, $\mathrm{mAh} \mathrm{g}_{\mathrm{Si}}{ }^{-1}$ as shown in
Fig. 6c. A linear fit from experimental data shows a slope of

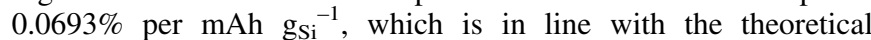

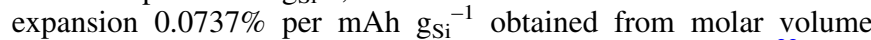
changes in crystalline phases of $\mathrm{Li}-\mathrm{Si}$ alloying reaction. ${ }^{22}$ It is hypothesized that external pressure that is normally present in practical cells modifies expansion behavior resulting from binder itself, whereas the absence of the pressure displays more characteristic volume change coming from binder and its interaction with electrode materials. Moreover, when the pressure is applied, Si alloy particles may find a certain resistance toward the out-of-plane direction, which then results in a lower out-of-plane expansion and a more in-plane expansion.

\section{Conclusions}

In this work, we have used in situ dilatometry, optical microscopy and ex situ SEM in order to investigate the effect of the selected binders (i.e. LiPAA, PVdF, and PVA) on the volume changes of $\mathrm{Si}$ alloy containing anodes. The results demonstrate that the electrode with LiPAA, which exhibited the greatest volume expansion also, demonstrated the highest cyclability and reversibility during lithiation and delithiation. We tentatively attribute this result to the strength of the interaction between binder and silicon particles (via ion-dipole interactions) dominating the electrode properties. Dilatometry results demonstrated that SEI layer formation at the early stage of first lithiation for all electrodes is unlikely to contribute out-of-plane expansion at the electrode level. It was observed that the 1st complete cycle of the LiPAA-containing electrode (i.e. expansion and then contraction) resulted in an increase in electrode porosity, which buffered against subsequent volume 
(a)

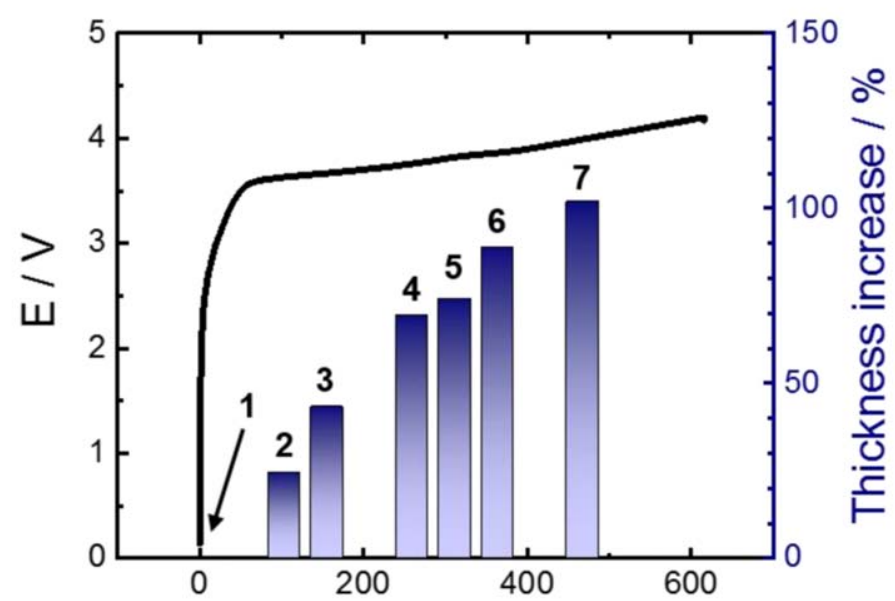

Anode specific capacity / $\mathrm{mAh} \mathrm{g}^{-1}$

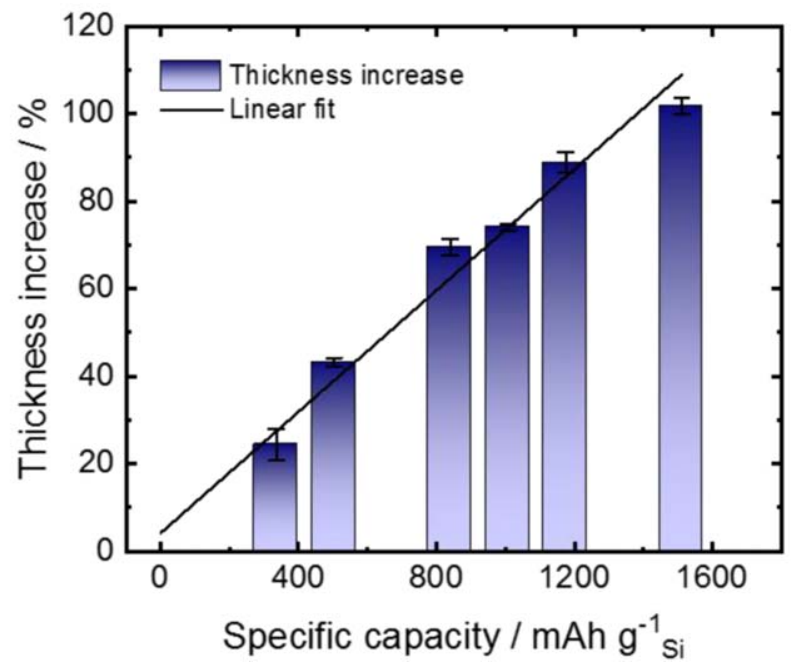

(b)

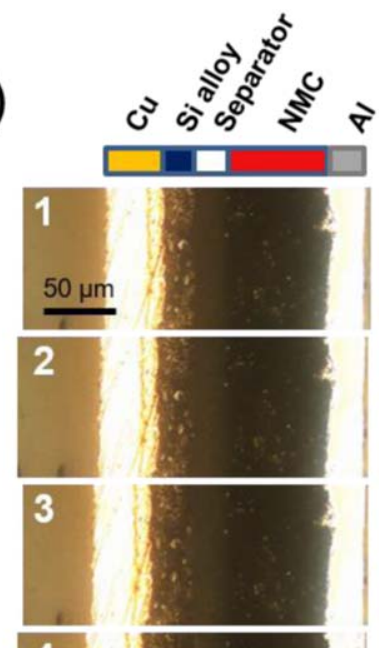

4

5

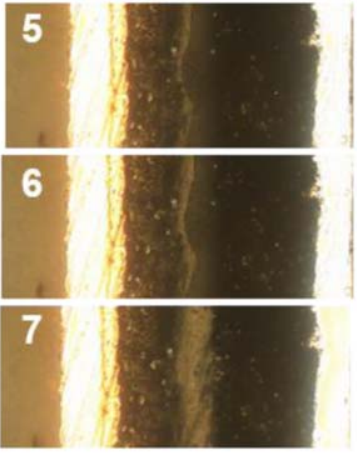

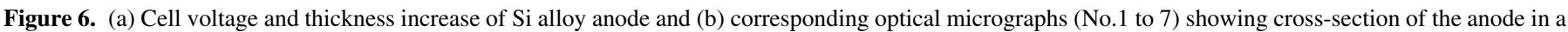

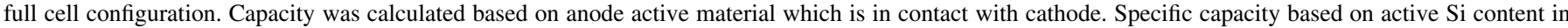
the alloy (31 wt.\%) is calculated and displayed in (c). Linear fit was made by Origin ${ }^{\circledR}$ (solid line).

changes. This was verified semi-quantitatively via cross sectional SEM analysis using the Avizo ${ }^{\mathrm{TM}}$. The proof-of-concept experiments using in situ optical microscopy (IOM) were carried out with the best performing LiPAA electrodes. It was found that the expansion of LiPAA appeared to initiate at the anode-separator interface, before evolution towards the separator, resulting in an apparent increase in surface roughness. The results also demonstrated that LiPAA electrode in the IOM cell expands much less compared to the same electrode in the dilatometer cell, which indicates that the pressure present in the cells has a great impact on on-plane electrode expansion. One key finding of this body of work is that larger volume expansions are not necessarily harmful to longer term cyclability, and that the cohesion strength of the electrode (a function of binder choice) is also a critical descriptor which should be considered during future research.

\section{Acknowledgments}

All the authors would like to acknowledge the financial support from the European Union's H2020 Framework Programme for research, technological development and demonstration (H2020GV-2014) under grant agreement no653531 (FIVEVB). Moreover, MM and MWM acknowledge the financial support of the German Research Foundation (DFG) under Project ID 390874152 (POLiS
Cluster of Excellence). This work contributes to the research performed at CELEST (Center for Electrochemical Energy Storage Ulm-Karlsruhe). Finally, we thank 3 M Germany (Neuss) for kindly providing the silicon alloy material and N. Drewett (CIC energigune) and M. Mancini (ZSW) for fruitful discussion.

\section{ORCID}

Dong-Hwan Yoon (D) https://orcid.org/0000-0003-1133-7613

Mario Marinaro (D) https://orcid.org/0000-0002-5954-0357

\section{References}

1. M. T. Mcdowell, S. W. Lee, W. D. Nix, and Y. Cui, "25th anniversary article understanding the lithiation of silicon and other alloying anodes for lithium-ion batteries." Adv. Mater., 25, 4966 (2013).

2. M. N. Obrovac and V. L. Chevrier, "Alloy negative electrodes for li-ion batteries." Chem. Rev., 114, 11444 (2014).

3. J.-S. Bridel, T. Azaïs, M. Morcrette, J.-M. Tarascon, and D. Larcher, "In Situ observation and long-term reactivity of $\mathrm{Si} / \mathrm{C} / \mathrm{CMC}$ composites electrodes for li-ion batteries." J. Electrochem. Soc., 158, A750 (2011).

4. B. Scrosati, J. Garche, and W. Tillmetz, Advances in Battery Technologies for Electric Vehicles (Woodhead Publishing, Cambridge, United Kingdom) 1st ed. (2015).

5. C. Erk, T. Brezesinski, H. Sommer, R. Schneider, and J. Janek, "Toward silicon anodes for next-generation lithium ion batteries: a comparative performance study of various polymer binders and silicon nanopowders." ACS Appl. Mater. Interfaces, 5, 7299 (2013). 
6. D. Mazouzi, Z. Karkar, C. R. Hernandez, P. J. Manero, D. Guyomard, L. Roué, and B. Lestriez, "Critical roles of binders and formulation at multiscales of siliconbased composite electrodes." J. Power Sources, 280, 533 (2015).

7. C. C. Nguyen and B. L. Lucht, "Comparative study of fluoroethylene carbonate and vinylene carbonate for silicon anodes in lithium ion batteries." J. Electrochem. Soc., 161, A1933 (2014)

8. C. Xu, F. Lindgren, B. Philippe, M. Gorgoi, F. Björefors, K. Edström, and T. Gustafsson, "Improved performance of the silicon anode for li-ion batteries: understanding the surface modification mechanism of fluoroethylene carbonate as an effective electrolyte additive." Chem. Mater., 27, 2591 (2015).

9. M. Marinaro, D. Bresser, E. Beyer, P. Faguy, K. Hosoi, H. Li, J. Sakovica, K. Amine, M. Wohlfahrt-Mehrens, and S. Passerini, "Bringing forward the development of battery cells for automotive applications: perspective of R\&D activities in China, Japan, the EU and the USA." J. Power Sources, 459, 228073 (2020).

10. M. N. Obrovac and L. Christensen, "Structural changes in silicon anodes during lithium insertion/extraction." Electrochem. Solid-State Lett., 7, A93 (2004).

11. R. Schmuch, R. Wagner, G. Hörpel, T. Placke, and M. Winter, "Performance and cost of materials for lithium-based rechargeable automotive batteries." Nat. Energy, 3, 267 (2018).

12. G. Berckmans et al., "Electrical characterization and micro X-ray computed tomography analysis of next-generation silicon alloy lithium-ion cells." World Electr. Veh. J., 9, 1 (2018).

13. L. De Sutter, G. Berckmans, M. Marinaro, J. Smekens, Y. Firouz, M. WohlfahrtMehrens, J. Van Mierlo, and N. Omar, "Comprehensive aging analysis of volumetric constrained lithium-ion pouch cells with high concentration siliconalloy anodes." Energies., 11, 5 (2018).

14. G. Berckmans, L. De Sutter, M. Marinaro, J. Smekens, J. Jaguemont, M. WohlfahrtMehrens, J. van Mierlo, and N. Omar, "Analysis of the effect of applying external mechanical pressure on next generation silicon alloy lithium-ion cells." Electrochim. Acta, 306, 387 (2019)

15. L. D. Sutter, G. Berckmans, M. Marinaro, M. Wohlfahrt-Mehrens, M. Berecibar and J. V. Mierlo, "Mechanical behavior of silicon-graphite pouch cells unde external compressive load: implications and opportunities for battery pack design." J. Power Sources, 451, 227774 (2020).

16. V. Müller, R.-G. Scurtu, M. Memm, M. A. Danzer, and M. Wohlfahrt-Mehrens, "Study of the influence of mechanical pressure on the performance and aging of Lithium-ion battery cells." J. Power Sources, 440, 227148 (2019).

17. V. Müller, R.-G. Scurtu, K. Richter, T. Waldmann, M. Memm, M. A. Danzer, an M. Wohlfahrt-Mehrens, "Effects of mechanical compression on the aging and the expansion behavior of $\mathrm{Si} / \mathrm{C}$-Composite|NMC811 in different lithium-ion battery cell formats." J. Electrochem. Soc., 166, A3796 (2019).

18. M. N. Obrovac, L. Christensen, D. B. Le, and J. R. Dahn, "Alloy design for lithiumion battery anodes." J. Electrochem. Soc., 154, A849 (2007).

19. V. L. Chevrier, L. Liu, D. B. Le, J. Lund, B. Molla, K. Reimer, L. J. Krause L. D. Jensen, E. Figgemeier, and K. W. Eberman, "Evaluating Si-based material for li-ion batteries in commercially relevant negative electrodes." J. Electrochem. Soc., 161, A783 (2014).

20. T. W. Kwon, J. W. Choi, and A. Coskun, "The emerging era of supramolecular polymeric binders in silicon anodes." Chem. Soc. Rev., 47, 2145 (2018).

21. A. Magasinski, B. Zdyrko, I. Kovalenko, B. Hertzberg, R. Burtovyy, C. F Huebner, T. F. Fuller, I. Luzinov, and G. Yushin, "Toward efficient binders for Li-ion battery Si-based anodes: polyacrylic acid." ACS Appl. Mater. Interfaces, 2, 3004 (2010).

22. D. Y. W. Yu, M. Zhao, and H. E. Hoster, "Suppressing vertical displacement of lithiated silicon particles in high volumetric capacity battery electrodes." ChemElectroChem., 2, 1090 (2015).

23. R. Kumar, J. H. Woo, X. Xiao, and B. W. Sheldon, "Internal microstructural changes and stress evolution in silicon nanoparticle based composite electrodes." J. Electrochem. Soc., 164, A3750 (2017).

24. M. H. Ryou et al., "Mussel-inspired adhesive binders for high-performance silicon nanoparticle anodes in lithium-ion batteries." Adv. Mater., 25, 1571 (2013).

25. A. Tranchot, H. Idrissi, P. X. Thivel, and L. Roué, "Impact of the Slurry pH on the expansion/contraction behavior of silicon/carbon/carboxymethylcellulose electrodes for li-ion batteries." J. Electrochem. Soc., 163, A1020 (2016).

26. T. Kwon, Y. K. Jeong, I. Lee, T.-S. Kim, J. W. Choi, and A. Coskun, "Systematic molecular-level design of binders incorporating meldrum's acid for silicon anodes in lithium rechargeable batteries." Adv. Mater., 26, 7979 (2014).
27. J. Song, M. Zhou, R. Yi, T. Xu, M. L. Gordin, D. Tang, Z. Yu, M. Regula, and D. Wang, "Interpenetrated gel polymer binder for high-performance silicon anodes in lithium-ion batteries." Adv. Funct. Mater., 24, 5904 (2014).

28. C. H. Jung, K. H. Kim, and S. H. Hong, "Stable silicon anode for lithium-ion batteries through covalent bond formation with a binder via esterification." ACS Appl. Mater. Interfaces, 11, 26753 (2019).

29. Y. Cho, J. Kim, A. Elabd, S. Choi, K. Park, T. W. Kwon, J. Lee, K. Char, A. Coskun, and J. W. Choi, "A pyrene-poly(acrylic acid)-polyrotaxane supramolecular binder network for high-performance silicon negative electrodes." $A d v$ Mater., 31, 1 (2019).

30. R. Kasinathan, M. Marinaro, P. Axmann, and M. Wohlfahrt-Mehrens, "Influence of the molecular weight of poly-acrylic acid binder on performance of si-alloy/graphite composite anodes for lithium-ion batteries." Energy Technol., 6, 1 (2018).

31. G. Jeong, S. M. Lee, N. S. Choi, Y. Kim, and C. K. Lee, "Stabilizing dimensiona changes in Si-based composite electrodes by controlling the electrode porosity: an in situ electrochemical dilatometric study." Electrochim. Acta, 56, 5095 (2011).

32. A. Tranchot, H. Idrissi, P.-X. Thivel, and L. Roué, "Influence of the Si particle size on the mechanical stability of Si-based electrodes evaluated by in-operando dilatometry and acoustic emission." J. Power Sources, 330, 253 (2016).

33. J. Huesker, L. Froböse, A. Kwade, M. Winter, and T. Placke, "In Situ dilatometric study of the binder influence on the electrochemical intercalation of bis(trifluoromethanesulfonyl) imide anions into graphite." Electrochim. Acta, 257, 423 (2017).

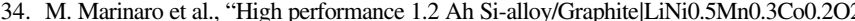
prototype Li-ion battery." J. Power Sources, 357, 188 (2017).

35. H.-J. Yu, K.-P. Hong, M.-S. Sung, S. Lee, K. Yoon Sheem, and S.-S. Kim "Enhanced dilation properties of silicon-silicide, $\mathrm{Si}-\mathrm{TiFeSi2}$, nanocomposite as a lithium battery anode." ECS Electrochem. Lett., 2, A10 (2012).

36. P. Limthongkul, Y.-I. Jang, N. J. Dudney, and Y.-M. Chiang, "Electrochemically driven solid-state amorphization in lithium-silicon alloys and implications for lithium storage." Acta Mater., 51, 1103 (2003).

37. D. Yoon, M. Marinaro, P. Axmann, and M. Wohlfahrt-Mehrens, "Quantitative analysis of consumption of fluoroethylene carbonate additives on silicon alloy anodes." J. Electrochem. Soc., 165, A2467 (2018).

38. User Manual ECD-3 Release 1.32 (EL-CELL GmbH, Hamburg) (2016).

39. I. A. Profatilova, C. Stock, A. Schmitz, S. Passerini, and M. Winter, "Enhanced thermal stability of a lithiated nano-silicon electrode by fluoroethylene carbonate and vinylene carbonate." J. Power Sources, 222, 140 (2013).

40. M. Wetjen, D. Pritzl, R. Jung, S. Solchenbach, R. Ghadimi, and H. A. Gasteiger "Differentiating the degradation phenomena in silicon-graphite electrodes for lithium-ion batteries." J. Electrochem. Soc., 164, A2840 (2017).

41. T. Jaumann, J. Balach, M. Klose, S. Oswald, U. Langklotz, A. Michaelis, J. Eckert, and L. Giebeler, "SEI-component formation on sub $5 \mathrm{~nm}$ sized silicon nanoparticles in Li-ion batteries: the role of electrode preparation, FEC addition and binders." Phys. Chem. Chem. Phys., 17, 24956 (2015).

42. A. L. Michan, B. S. Parimalam, M. Leskes, R. N. Kerber, T. Yoon, C. P. Grey, and B. L. Lucht, "Fluoroethylene carbonate and vinylene carbonate reduction: Understanding lithium-ion battery electrolyte additives and solid electrolyte interphase formation." Chem. Mater., 28, 8149 (2016).

43. R. Jung, M. Metzger, D. Haering, S. Solchenbach, C. Marino, N. Tsiouvaras, C. Stinner, and H. A. Gasteiger, "Consumption of fluoroethylene carbonate (FEC) on Si-C composite electrodes for li-ion batteries." J. Electrochem. Soc., 163, A1705 (2016).

44. R. Petibon, V. L. Chevrier, C. P. Aiken, D. S. Hall, S. R. Hyatt, R. Shunmugasundaram, and J. R. Dahn, "Studies of the capacity fade mechanism of LiCoO 2 /si-alloy: graphite cells." J. Electrochem. Soc., 163, A1146 (2016).

45. E. Peled, "Lithium stability and film formation in organic and inorganic electrolyte for lithium battery systems.", ed. J. P. Gabano Lithium Batter. (New York) (Academic) (1983)

46. E. Peled and H. Straze, "The kinetics of the magnesium electrode in thiony chloride solutions." J. Electrochem. Soc., 124, 1030 (1977).

47. E. Peled, F. Patolsky, D. Golodnitsky, K. Freedman, G. Davidi, and D. Schneier, "Tissue-like silicon nanowires-based three-dimensional anodes for high-capacity lithium ion batteries." Nano Lett., 15, 3907 (2015).

48. D. S. M. Iaboni and M. N. Obrovac, "Li15Si4 formation in silicon thin film negative electrodes." J. Electrochem. Soc., 163, A255 (2016).

49. C. Y. Chen, A. Sawamura, T. Tsuda, S. Uchida, M. Ishikawa, and S. Kuwabata "Visualization of $\mathrm{Si}$ anode reactions in coin-type cells via operando scanning electron microscopy." ACS Appl. Mater. Interfaces, 9, 35511 (2017). 